\title{
Recreating Bone Stock: A Case of Intrapelvic Broken Cup Dislocation
}

\section{Trecci $\mathrm{A}^{*}$ and Imarisio D}

Reginamontisregalis Hospital, Italy

*Corresponding author: Trecci A, Reginamontisregalis Hospital, Via S. Rocchetto, 99, 12084 Mondovì CN, Italy

Submission: 海 October 27, 2017; Published: 海 August 21, 2018

\begin{abstract}
Total hip arthroplasty (THA) is an increasingly common procedure; more than 1 million hip arthroplasties are implanted worldwide per year [1]. By dedicating this procedure to ever younger patients, revision of hip arthroplasties is to be expected to increase in the future. Periacetabular bone loss remains the greatest challenge in revision hip surgery [2-5]. The general principles in treatment of periacetabular bone loss still include restoration of bony continuity between the ilium and the ischium, and reconstruction of the anatomical hip center [6,7]. Intrapelvic cup protrusion provides many challenges, from implant removal, as nerves and vessels are at risk for injury, to the need to use massive acetabular allografts to reconstruct bone loss [8-10].
\end{abstract}

Girard et al. [3] have established an effective strategy to reduce complications to a minimum, while performing a revision in presence of a pelvic protrusion. We present the case of an acute intrapelvic migration of a broken acetabular component, and the strategy used to perform a successful revision

\section{Case Report}

The patient (female, 77 years at the time of observation) had undergone surgery for total hip arthroplasty in 2002. In 2012 she began complaining about intermittent hip pain, apparently not load-related. The X-rays showed periacetabular radiolucency. She wasn't proposed a revision of the implant (Figure 1). In 2013, she developed a sudden right hip pain, and at this time was brought to our attention for treatment. X rays showed the broken cup (CLS, Zimmer, Warsaw, Indiana) protruding inside the pelvis (Figure
2). CT scans were obtained, to evaluate bone stock loss and the relationship between the protruding cup and the vessels (Figure 3). As they were on proximity, a subperitoneal approach was used to remove the hardware, and the the revision was performed with a posterolateral approach. The Paprosky was graded 2C. The gap was filled with homologous bone chips, augmented with platelet rich plasma (PRP). A Burch-Schneider (Zimmer, Warsaw, Indiana) cage was used to bridge the acetabular floor defect. As the stem was well fixed, it did not require revision (Figure 4).

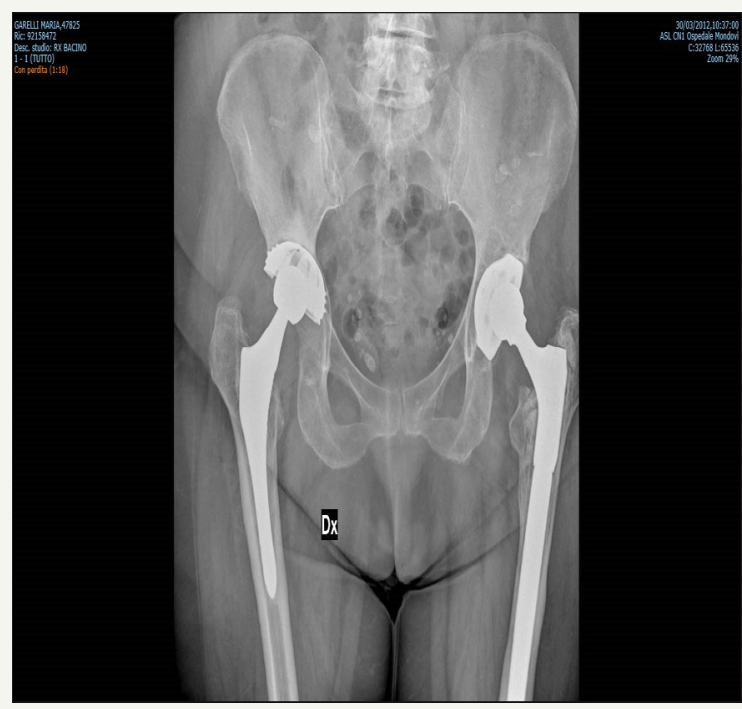

Figure 1: Radiolucency around the cup. 


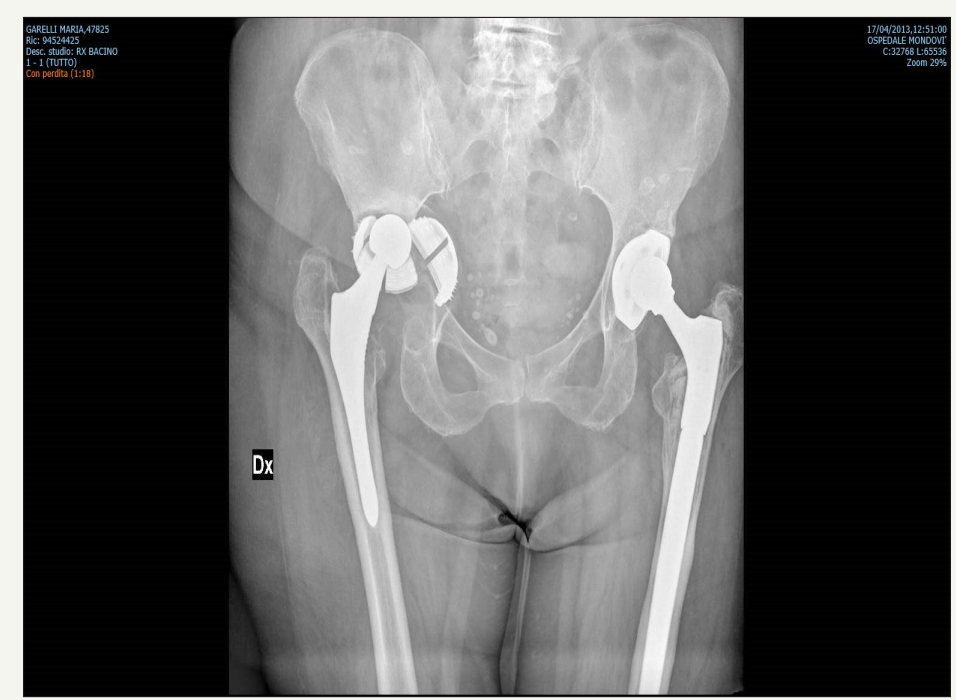

Figure 2: Protrusion of the broken cup.

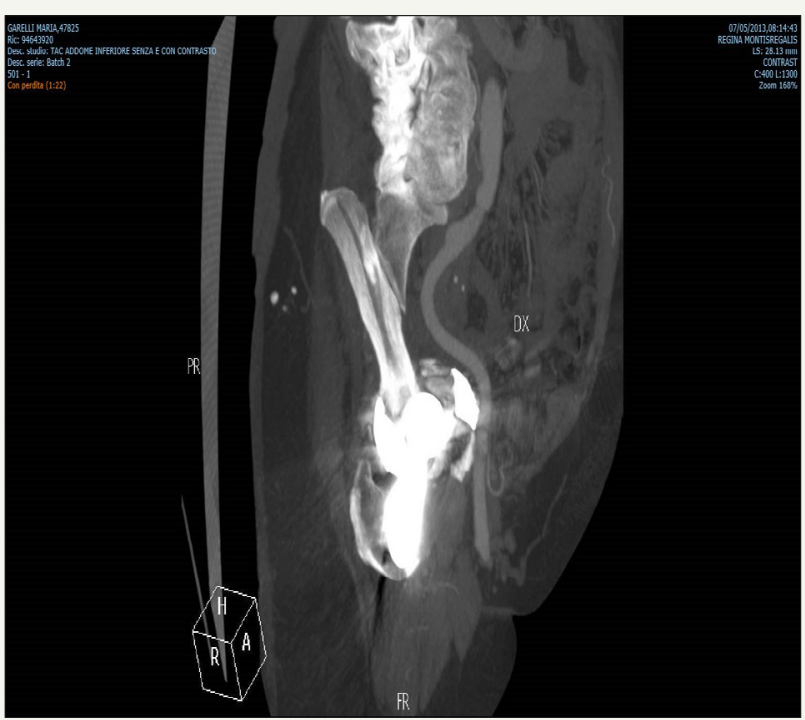

Figure 3: CT scans showing relationship between the cup fragments and the blood vessels.

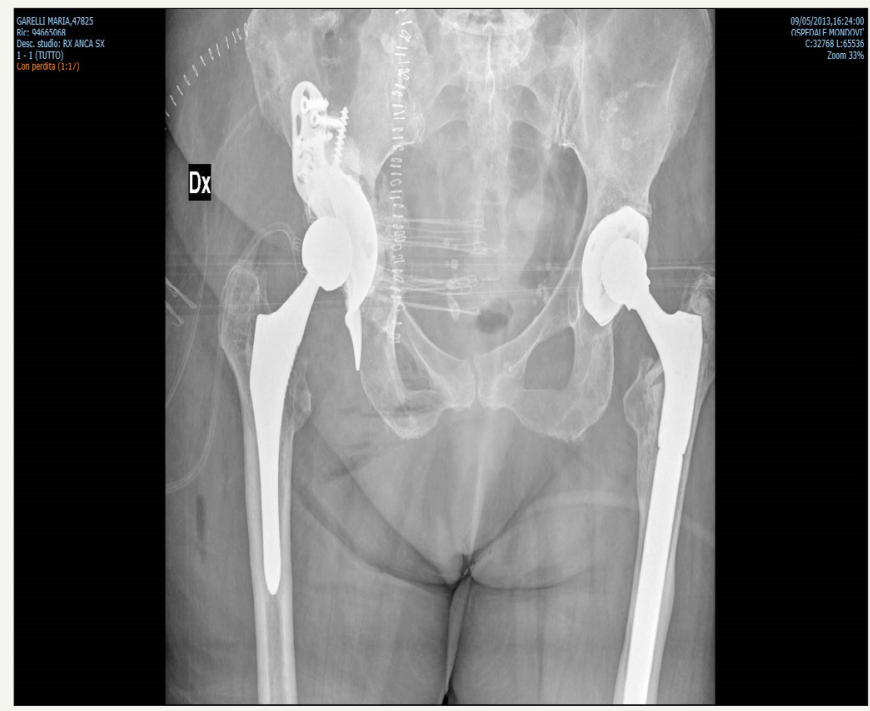

Figure 4: Postoperative $\mathrm{x}$ ray. 


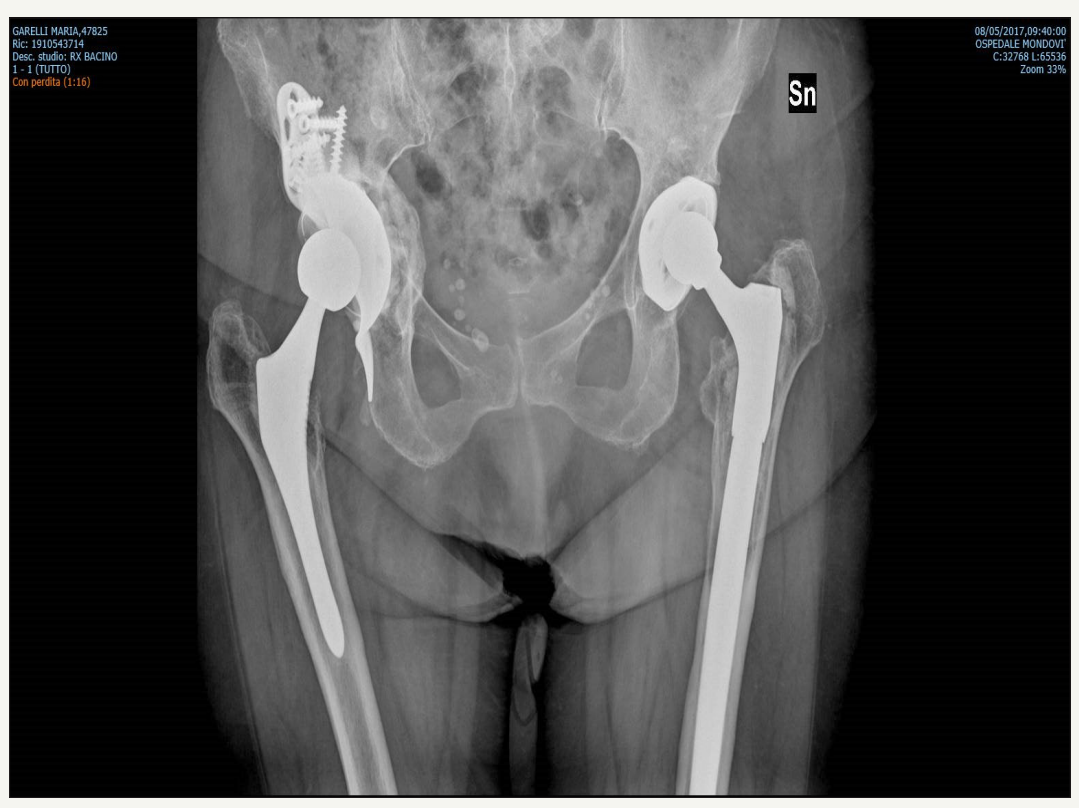

Figure 5: 4 years follow up, good integration.

Active motion and partial weight bearing were started immediately after surgery. At 2 months, no resorption of the graft was detected, and full weight bearing was allowed. At 4 years the patient is pain free, with a $\mathrm{x}$ ray showing satisfying graft integration, and bone stock reconstitution (Figure 5).

\section{Conclusion}

Revision of an intrapelvic-dislocated acetabular cup is a complex procedure requiring thorough planning and a surgeon well versed in revision surgery.

\section{References}

1. Kurtz S, Ong K, Lau E, Mowat F, Halpern M (2007) Projections of primary and revision hip and knee arthroplasty in the United States from 2005 to 2030. J Bone Joint Surg Am 89(4): 780-785.

2. Paprosky WG, Perona PG, Lawrence JM (1994) Acetabular defect classification and surgical reconstruction in revision arthroplasty. J Arthroplasty 9(1): 33-44.

3. Girard J, Blairon A, Wavreille G, Migaud H, Senneville E (2011) Total hip arthroplasty revision in case of intra-pelvic cup migration: designing a surgical strategy. Orthop Traumatol Surg Res 97(2): 191-200.
4. Vives P, Delestang M, Pallot R, Cazeneuve JP (1989) Le descellementaseptique. définitions-classifications. Rev Chir Orthop 75(Suppl 1): 29-31.

5. Epinette JA (2012) Outcome studies in hip and knee arthroplasty: a 14year experience with the orthowave software suite. J Bone Joint Surg Br 94: 63.

6. Merle d'Aubigné R (1970) Numerical classification of the function of the hip. Rev Chir Orthop 56: 481-486.

7. Harris WH (1969) Traumatic arthritis of the hip dislocation and acetabular fractures: treatment by meld arthroplasty. An end-result study using a new method of result evaluation. J Bone Joint Surg Am 51(4): 737-755.

8. Del Gaizo DJ, Kancherla V, Sporer SM, Paprosky WG (2012) Tantalum augments for Paprosky IIIA defects remain stable at midterm follow-up. Clin Orthop Relat Res 470(2): 395-401.

9. Dreinhofer KE, Dieppe P, Sturmer T, Gratz GD, Floren M, et al. (2006) Indications for total hip replacement: comparison of assessments of orthopaedic surgeons and referring physicians. Ann Rheum Dis 65(10): $1346-1350$

10. Malchau H, Herberts P, Eisler T, Garellick G, Soderman P (2002) The swedish total hip replacement register. J Bone Joint Surg Am 84A(Suppl 2): $2-20$.

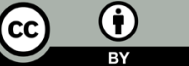

Creative Commons Attribution 4.0 International License

For possible submissions Click Here

\section{Submit Article}

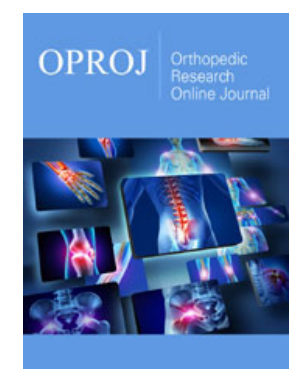

\section{Orthopedic Research Online Journal}

\section{Benefits of Publishing with us}

- High-level peer review and editorial services

- Freely accessible online immediately upon publication

- Authors retain the copyright to their work

- Licensing it under a Creative Commons license

- Visibility through different online platforms 